\title{
A política indigenista, para além dos mitos da Segurança Nacional
}

\author{
RICARDO CAVALCANTI-SCHIEL
}

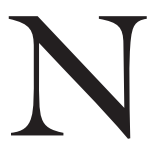

O DIA 16 de abril de 2008, o comandante militar da Amazônia, general Augusto Heleno Ribeiro Pereira, deslocou-se do seu posto de comando em Manaus para participar como palestrante de um seminário promovido pelo Clube Militar, no Rio de Janeiro, intitulado curiosamente (por seu inusitado alarmismo) "Brasil, ameaças à sua soberania". Cuidadosamente programado para estabelecer um contraponto entre vozes de tons nacionalistas e de tons políticos (bastante) conservadores, à cabeça das quais o advogado Ives Gandra Martins e o professor Denis Rosenfield (convidado, mas que não compareceu), o evento acabou sendo catalisado pelo tema da política indigenista brasileira na Amazônia, a partir do caso emblemático da demarcação de terras indígenas na fronteira nordeste de Roraima.

As estrondosas declarações críticas sobre a política indigenista, proferidas pelo general Heleno nesse evento, precedidas de outras que fizera uma semana antes, em um curso promovido pela Federação das Indústrias do Estado de São Paulo (Fiesp) e pelo evento judicial da liminar concedida pelo Supremo Tribunal Federal (STF) que paralisou a desintrusão de não índios da Terra Indígena Raposa/Serra do Sol, em Roraima, repercutiram imediatamente na mídia brasileira. ${ }^{1}$ Elas acabaram servindo de âncora discursiva, a partir da qual rapidamente desdobrou-se (ou inflou-se) o alarmismo implícito da iniciativa do Clube Militar, por meio do fantasma retórico de uma iminente ameaça à segurança nacional: a da "balcanização" étnica, capitaneada por ONG internacionais, por meio da instrumentalização dos povos indígenas brasileiros, que poderia até mesmo desembocar numa perigosa cascata de processos “secessionais" do território nacional, especialmente na Amazônia, e mais precisamente nas faixas de fronteira. Aparentemente (apenas) retirado de foco o perigo amazônico de um militantismo verde, a retórica da Segurança Nacional voltaria agora suas baterias contra o perigo de um militantismo pele-vermelha.

Essa alquimia de conspiração internacional com infiltração onguista e com a instrumentalização de uma plataforma “étnica” vem sendo há algum tempo urdida no caldeirão ideológico de grupos ultranacionalistas, vinculados a militares da reserva, que trabalham ativamente para aliciar os comandantes da ativa e estabelecer uma rede de apoios na sociedade civil, a partir de um inflamado 
discurso contra a "cobiça internacional da Amazônia" e o "imperialismo" de uma "oligarquia do capital". Fazendo uso de apelos discursivos próximos a certos motes que já foram considerados "radicais" da esquerda, a arenga ideológica dessas posições imiscui-se até mesmo com bastante desenvoltura e ecletismo entre políticos e meios de comunicação digital ligados àquelas tendências, como o PC do B, especialmente. Seu núcleo irradiador, ao que tudo indica, é o Centro Brasileiro de Estudos Estratégicos (Cebres), que abriga os “órfãos” da Escola Superior de Guerra, congrega a rede social a partir dela produzida e um considerável número de oficiais de alta patente da reserva, que milita ativamente junto aos clubes das três armas e que se espraia por uma teia de portais da internet, de curioso e desconcertante (senão mesmo delirante) conteúdo político. ${ }^{2}$

Algumas semanas antes das manifestações bombásticas do general Heleno, o Exército se recusara a participar da operação de desintrusão de não índios da Terra Indígena Raposa/Serra do Sol, entregue então aos cuidados exclusivos da polícia federal, e, com uma ação coordenada de manifestações políticas pontuais organizadas pelo Cebres, preparou-se a cuidadosa orquestração que serviria de "base de lançamento" para o inflamado discurso contra a política indigenista brasileira, pronunciado pelo comandante militar da Amazônia. ${ }^{3}$

Poucos dias depois das declarações do general Heleno, um ex-presidente daquele mesmo clube, e que também foi comandante militar da Amazônia, o general Luiz Gonzaga Schroeder Lessa, um reconhecido e devotado nacionalista (mas não por isso menos espalhafatoso), publicava uma nota no website do clube, em que acusava, como culminação dessa presumida nova conspiração internacional, a recente Declaração Universal dos Direitos dos Povos Indígenas, aprovada pela ONU em 13 de setembro passado, com o voto favorável do Brasil:

Caso a Declaração venha a ser referendada pelo Congresso, ganhará força de emenda constitucional, conforme prevê a própria Constituição. [...] Em tese, nada impediria que algum destes vários líderes indígenas, muito bem instruídos e preparados, declarasse a independência de sua "nação", apartada do Brasil.

A se confirmar essa tendência, teremos retalhado o Brasil em 227 nações, com 180 diferentes idiomas. O crime contra o Brasil e sua soberania e unidade territorial terá sido perpetrado. Onde está a sociedade civil que não se manifesta? ${ }^{4}$

A "sociedade civil" manifestou-se, seja por meio da adesão imediata a um certo nacionalismo naïf, expressa por uma multiplicidade de declarações de apoio às sobressaltadas preocupações do general Heleno, seja por meio do ensaio de instrumentalização político-partidária do alvoroço midiático provocado por aquelas manifestações, expressa na "ameaça" de convocação do mesmo general pela Comissão de Relações Exteriores e Defesa Nacional do Senado, controlada pelos dois principais partidos de oposição (DEM e PSDB), com vistas a inflar artificiosamente uma "crise militar" no governo, seja ainda por meio das reações contrárias às manifestações do general, expressas pelos canais jornalísticos, sobretudo por antropólogos, que buscaram demonstrar que não só aquele comandante militar estava encontrando chifre em cabeça de cavalo, com um sensacionalis- 
mo alarmista malposto em todos os seus termos, como também que ele acabava se prestando, apenas, a fazer o jogo de um lobby latifundiário amazônico, com conexões em um amplo campo político conservador.

Com efeito, na semana seguinte à das declarações do impetuoso general, o jornalista Janio de Freitas lembrava, em uma matéria na Folha de S.Paulo, que aquele protagonista fardado, "tido como identificado com a velha linha dura, constitui-se em uma figura polêmica", que

chegou ao noticiário por ocasião das investigações em torno do (ex) juiz Nicolau dos Santos Neto, quando foram descobertos quase 200 telefonemas desse hoje condenado para o Gabinete de Segurança Institucional da Presidência da República, cerca de metade reconhecida pelo general como destinada a ele. ${ }^{5}$

As "ligações perigosas" do general e sua controversa participação no comando da força internacional da ONU no Haiti - de onde saiu sob a acusação, feita às suas tropas, por um relatório produzido pelo Centro de Justiça Global e pela Universidade Harvard, de cumplicidade com a sistemática violação dos direitos humanos naquele país - seguramente pesaram para que ele fosse considerado uma carta política problemática, mesmo pelos partidos de oposição ao governo Lula. ${ }^{6}$

O apelo fácil do discurso nacionalista e o entroncamento da veemente condenação à política indigenista feita pelo então comandante Militar da Amazônia com a generalidade de um discurso anti-indígena, sustentado pela teia de interesses econômicos (sobretudo fundiários) na região, acabaram, no entanto, garantindo, para essa reiterada retórica da "ameaça à segurança nacional", ainda que sobreincidente num novo objeto, um nicho de apoio político que deve ser levado em consideração ao se ponderarem, doravante, os rumos das relações de certos setores militares brasileiros com outros segmentos da sociedade nacional.

Obviamente, como sempre, o futuro melhor mostrará a conformação sociológica em que esse jogo de alianças vai resultar, e se esses setores militares, caracteristicamente mais vinculados ao conservadorismo político, conseguirão sustentar sua hegemonia discursiva na corporação, sob a forma da reiteração de uma interpretação particular para uma "preocupação amazônica" mais genérica, largamente incidente no pensamento militar dos últimos 50 anos. Como se sabe, essa "preocupação", que atende pelo nome de geopolítica, vem há várias décadas sendo modulada pela predeterminação simbólica (e ubíqua) da ideia da cobiça internacional (Leirner, 1995) e pela pressuposição de um permanente estado de insegurança nacional na região (Pinto, 2002).

Desde já, no entanto, e a despeito de uma dimensão localista das imediatas alianças políticas implícitas, é razoavelmente evidente que manifestações como as dos generais que vínhamos mencionando, bem como a iniciativa do Clube Militar, almejam alçar a "questão indígena" a um certo patamar de inquietação ideológica. Isso vem sendo insinuado desde os debates em torno do Projeto Calha Norte, na segunda metade da década de 1980, mas agora certos elementos discursivos 
parecem ganhar tonalidades mais precisas. O que talvez tenhamos como tinturas novas nesse nem tão novo aparato discursivo é a conjunção de alguns de seus velhos expedientes retóricos com um possível (ou talvez mesmo iminente) debate sobre alguns termos de regulação jurídica, que incidem sobre temas (a propósito dos quais pesa uma considerável disputa discursiva) que rondam a atualidade não apenas nacional, como também internacional: temas como multiculturalismo, diversidade, etnicidade, direitos coletivos; enfim, o estatuto sociojurídico não mais de um ideal (ou pressuposto) republicano da "igualdade", mas sim daquele hoje alentado por uma certa agenda pós-moderna: o da “diferença”.

De outra parte, a específica articulação de instâncias políticas que sustentam a lógica discursiva daquela pretendida condenação lançada pelo general Heleno à política indigenista brasileira não apenas traz à tona o rastro de um movimento histórico que pode ser remontado às alianças políticas gestadas durante o projeto de colonização da Amazônia do assim chamado "regime militar" (expresso em seu lema “integrar para não entregar"), como traz à tona também uma tensão que perpassa a história da própria política indigenista brasileira no século XX. Desse modo, a contundente crítica do general Heleno a essa política é, em termos históricos, tanto sintomática - se consideramos um período mais recente - quanto anacrônica - se consideramos uma já larga tradição constituída pelo Estado brasileiro (com a presença fundacional, inclusive, dos militares), a respeito do trato com os povos indígenas. Assim, uma maneira de compreender melhor o contexto da inusitadamente polêmica "política indigenista brasileira" é escarafunchar, em termos analíticos, o significado das suas relações históricas.

Uma precaução bastante elementar na análise da política indigenista brasileira é a de distinguir as linhas gerais das políticas de Estado - sustentadas por uma diversidade de instâncias normativas e administrativas - da atuação (ou mesmo a "eficiência") dos órgãos indigenistas. Sinteticamente, isso nos recomenda o cuidado, até bastante óbvio, de não reduzir a política indigenista à atuação do órgão indigenista, ainda que ele tenha sido não apenas a principal ferramenta de execução dessa política, como também o depositário das místicas e das vocações que a perpassaram. A criação da Funai em 1967 pretendeu solucionar a exaustão política e administrativa a que chegara o órgão anterior, o Serviço de Proteção aos Índios, criado, por sua vez, em 1910, pelo marechal Rondon, e que, ainda assim, fora incapaz de evitar a extinção de 87 grupos indígenas entre 1900 e 1957.7

Críticas à corrupção, inépcia administrativa, ambiguidades de orientação e insuficiência (às vezes deliberada) de meios são recorrentes não apenas para a história da Funai, como também para a do seu antecessor; da mesma maneira como o reconhecimento do cultivo de uma mística da dedicação e de uma vocação de defesa dos índios por parte de um corpo de funcionários do Estado. Tanto não se pode reduzir toda a política indigenista atual à atuação da Funai quanto não se pode reduzir essa à condição de mero aparelho de Estado criado e subordinado à lógica da ditadura militar. Uma história de mais longo curso da 
política indigenista parece perpassar a especificidade dos órgãos indigenistas, ao mesmo tempo que lhes especifica continuamente um lugar, ainda que, muitas vezes, sob as contingências políticas, esse seja um lugar antes ideal que efetivo.

Em termos gerais, o século XX parece ter caracterizado um novo padrão genérico de relações dos poderes públicos brasileiros com os povos indígenas. Se nos períodos históricos precedentes essa relação oscilava entre a ocasional aliança (ou confrontação) militar, a "domesticação" subjugadora e o simples extermínio, circunstancialmente determinados pelo contato dos agentes colonizadores, o século passado deu lugar ao fenômeno da "proteção". Ambíguo em seu conteúdo, oscilando entre a tutela cerceadora e a promoção da autonomia relativa, a lógica da proteção significou, antes de mais nada (e no que poderíamos identificar como seus termos formais mais genéricos), o estabelecimento de uma relação direta, necessária e institucionalizada entre o Estado nacional e as populações indígenas. É compreensível que sua inspiração esteja no positivismo que embebeu a instituição militar e a tornou avalista de novas expectativas sobre a nacionalidade, com as quais a recente República ingressou no século XX.

É igualmente compreensível, portanto, que o mentor, tanto intelectual quanto "espiritual", do indigenismo de Estado tenha sido também um militar, o futuro marechal Rondon, encarregado de alcançar ( $e$, já àquela época também "integrar", mediante novas tecnologias de comunicação, a saber, o telégrafo) as longínquas fronteiras do extremo oeste do país, onde a presença pioneira do Estado tinha que se haver com a presença dos "silvícolas". É, assim, sintomático que esse indigenismo de Estado tenha vingado com a conformação de uma certa modernidade política, plenamente consagrada na década de 1930, pela qual o Estado Nacional se apresentava como o mentor de uma nova racionalidade administrativa e regulatória, por sobre o particularismo dos interesses das oligarquias regionais.

Em suma, o que acompanhou e tornou possível o então incipiente modelo rondoniano da proteção foi o padrão de um Estado Nacional "civilizador" que se superpunha e muitas vezes se opunha aos poderes oligárquicos regionais dos grotões, caracterizados em termos genéricos, no que diz respeito ao trato com os índios, por uma já histórica (ou "atávica") "incivilização" predatória. Não se tratava, portanto, de qualquer "proteção" aos índios, mas, antes de tudo, de uma proteção "nacional", que tomava as populações indígenas como parte de um patrimônio da nacionalidade, que devia ser integrado no (e pelo) espaço político do Estado Nacional, a despeito dos (e quase sempre contra os) particularismos locais. Não por acaso, já em 1910 o próprio Rondon emoldurara o sentido dessas relações sob termos que sintetizavam uma paridade de estatuto particularmente significativa entre comunidades indígenas e nacionalidade; significativa até mesmo para as preocupações hoje tão caras a alguns generais, e atinentes à presumida Segurança Nacional. Em uma de suas cartas, recentemente descoberta por funcionários da Funai em Amambaí (MS), Rondon comenta: 
O Serviço de Proteção na mão dos Estados seria a anarchia nos processos e nos meios; estaríamos expostos a meu ver, na extenção do território brasileiro applicado, aqui o extermínio, alli a catechese forçada, theologica ou metaphysica, e mais além o abandono. Ora, os índios não devem ser tratados como propriedade do Estado dentro de cujos limites ficam seus territórios, mas sim como nações autônomas, com as quaes queremos estabelecer relações de amisade.

Os governos estaduais, urgidos pela necessidade de fazer dinheiro sob a influência de interesses próximos, quasi nunca sabem resistir à tentação de dispor dos territórios dos índios sob o titulo de terras devolutas. Quanto à União, é impossível negar achar-se ella em uma posição muito mais favorável para considerar o problema de um ponto de vista mais geral, mais humano, desprendido de influições regionaes. (inédito, Museu do Índio, Rio de Janeiro; grafia original, grifo nosso)

As impressionantes palavras do então tenente-coronel Rondon contrastam significativamente com o esquecimento (ou a deliberada ignorância) com que outro recente ex-comandante militar da Amazônia, o general Claudio Barbosa de Figueiredo, ${ }^{8}$ nos desdobramentos do caso do general Heleno, pretendeu responder ao presidente da Funai, em um artigo publicado no jornal Gazeta do Povo, de Curitiba, em 6 de maio, ${ }^{9}$ asseverando que a afirmação deste último, de que a política indigenista brasileira seguia (ainda) os parâmetros estabelecidos pelo marechal Rondon, só podia ser uma "flagrante inverdade". Esse outro general defende que o legado rondoniano se resume ao ideal de uma integração indiferenciada dos índios (como individuos naturais, ou seja, descartado o pressuposto rondoniano da comunidade, subentendido no termo "nação", logo antes citado) a uma sociedade nacional genérica, e que uma pretensa "preservação da cultura indígena" seria apenas uma postura "condicionada por ideologias surgidas no exterior" que "chega às raias da irresponsabilidade" (provavelmente uma "irresponsabilidade" utilitarista diante dos bens culturais "incontestáveis" da "civilização", como se existisse apenas uma única "verdade" cultural).

Ao pretender, de sua parte, patrimonializar, para seus interesses corporativos (ou, ao menos, de uma parte da corporação militar), a imagem e o legado do velho marechal, esse outro general perde a noção dos fundamentos lógicos que dão sentido ao indigenismo rondoniano - ou seja, exatamente aqueles que "sobreviveram" ao discurso assimilacionista -, para aferrar-se a uma projeção imponderável: a miragem antropologicamente inconsistente de uma nacionalidade cultural presumidamente homogênea, ou, se se preferir, aquilo a que o velho marechal apropriadamente chamou de "catequese metafísica" dos índios.

O notável advento histórico carreado pelo programa positivista do modelo da proteção pode ser traduzido como a emergência simbólica do "índio nacional", por oposição à antiga dualidade entre índios aliados e inimigos, expressa, por exemplo, na clivagem tupis-tapuias do indigenismo oitocentista (cf. Carneiro da Cunha, 1992; Monteiro, 1992). Não obstante, é possível dizer também que, a partir daquele padrão lógico (e conceitual) fundamental, da relação necessária, 
direta e institucionalizada entre Estado Nacional e coletividades indígenas, que com toda justiça podemos chamar de "rondoniano", e sobre o qual se assentou a ideia da proteçã o, a política indigenista brasileira foi, historicamente, modificando as suas escalas. O advento da criação do Parque Indígena do Xingu, gestado desde 1952 e tornado efetivo em 1961, pode ser considerado como uma (se não a mais importante) dessas mudanças de escala. Ela representa o que também poderíamos chamar de um redimensionamento villas-boasiano (que implicou, na verdade, a aliança de uma série de atores políticos) ao modelo rondoniano, que o próprio Marechal Rondon viria a chancelar, segundo o testemunho dos seus diálogos com os irmãos Villas Bôas e sua participação direta na proposta de criação do Parque: o estabelecimento de grandes áreas vitais que garantissem a plena reprodução cultural de grupos indígenas.

Se o modelo anterior era semelhante aos das reservas norte-americanas, no qual os índios eram concentrados em torno de um posto indígena, para que o restante dos seus territórios ancestrais fosse liberado para a colonização agrária (o que poderíamos chamar de "modelo mato-grossense"), a partir do Parque Indígena do Xingu os territórios ancestrais de ocupação passaram a ser a base de reconhecimento de um hábitat social, e daí preservados como territórios culturais, e não, tão simplesmente, como propriedade produtiva (justificada pela mera subsistência material). Essa concepção viria a ser finalmente consagrada no artigo 231 da Constituição de 1988, que define como "terras indígenas" tanto aquelas habitadas pelos índios quanto aquelas "utilizadas para suas atividades produtivas, as imprescindíveis à preservação dos recursos ambientais necessários a seu bem-estar e as necessárias a sua reprodução física e cultural, segundo seus usos, costumes e tradições".

Esse mesmo dispositivo constitucional caracteriza também essas terras como "inalienáveis e indisponíveis, e os direitos sobre elas, imprescritíveis". Por oposição ao "mato-grossense", esse outro poderia ser chamado de "modelo amazônico". Sua relevância pode ser facilmente constatada uma vez que se considere que a região sobre a qual ele fundamentalmente viria a incidir, a Amazônia Legal, abriga hoje, de acordo com o cadastro do Sistema de Informação à Saúde Indígena (Siasi) da Fundação Nacional de Saúde (Funasa), 56,3\% da população indígena brasileira (Ministério da Saúde, 2007, p.23).

O caso xinguano foi exemplar também no que caracterizou como disputa entre o oportunismo dos interesses regionais e a ação regulatória e administrativa da União. Isolada e praticamente impenetrada durante séculos, a região dos formadores do Xingu era um dos assim chamados "brancos" no mapa do Brasil até o final da Segunda Guerra Mundial, quando uma nova sensibilidade nacional de premência estratégica de ocupação desses "brancos" levou à criação da Fundação Brasil Central, responsável por realizar a Expedição Roncador-Xingu. Cruzando a região dos ainda inamistosos índios xavantes, a Expedição chegou ao Alto Xingu, que até então só havia sido cruzada e documentada pelas duas 
expedições do antropólogo alemão Karl von den Steinen, no final do século XIX. Instalada por meio do contato pacífico com os índios, a expedição, já então comandada pelos irmãos Villas Bôas, lançou as bases da presença efetiva do Estado na região, que se tornou a referência incontornável de interlocução para os 14 povos indígenas que seriam abrigados no futuro Parque; presença que incluiu a abertura de um campo de pouso e base de comunicações da FAB (a Base do Jacaré), que então operava como ponto intermediário das rotas aéreas militares entre Rio (ou São Paulo) e Manaus. A base funcionou até a década de 1970, quando a abertura de outros campos de pouso regionais e o aumento da autonomia de voo tornaram-na obsoleta.

Já no início da década de 1950, ao se consagrar o sucesso da atuação da Fundação Brasil Central, as forças políticas locais, acantonadas no governo do Estado de Mato Grosso, de forma bastante similar ao que se passou recentemente em Roraima, tomaram a iniciativa de distribuir a seus favorecidos e clientes políticos as terras daquele "branco" do mapa, chegando a sobrepor várias vezes a entrega de um mesmo território. A justificativa retórica era, como sempre, a necessidade de impulsionar o progresso e a produção. Mas, à diferença da Terra Indígena Raposa/Serra do Sol, como a Amazônia mato-grossense não se constitui dos mesmos campos abertos de Roraima, e como os núcleos urbanos ainda estavam muito longe da área dos formadores do Xingu (e só viriam a ser constituídos por pequenos agricultores gaúchos ao final dos anos 1970), as terras entregues pelo governo de Mato Grosso, sobre as quais se assentou o Parque do Xingu, permaneceram resguardadas da invasão dos regionais, até que aqueles interesses vinculados à política local descobriram uma maneira de fazer bom negócio com essas terras, por meio da indústria da indenização judicial, sob a escusa da criação do Parque do Xingu.

Em 1987, o total das indenizações devidas judicialmente pela União por conta dessa indústria foi calculado pela Procuradoria-Geral da República em 102 bilhões de dólares, à época um terço do PIB brasileiro. Tal como atualmente ocorre com o caso Raposa/Serra do Sol, em Roraima, a capacidade de articulação política do lobby latifundiário nacional já tinha conseguido, fazendo uso aliás de provas fraudadas e laudos viciados, uma sentença favorável no STF. Se ela transitasse em julgado, produziria uma jurisprudência capaz de gerar uma impressionante sangria dos cofres públicos, bem como um precedente capaz de transformar quaisquer terras da União em mero botim potencial da aventura fundiária e do casuísmo político, tal como agora, mais uma vez, correu-se o risco de ocorrer, com um julgamento extemporâneo e casuísta, pelo mesmo STF, das competências do Executivo quanto à demarcação da Terra Indígena Raposa/Serra do Sol.

No caso das terras do Parque do Xingu, entretanto, ao constatar o tamanho do esbulho ao patrimônio público, a Procuradoria-Geral da República lançou mão de um tipo de peritagem até então inédita na história do Judiciário brasileiro, e que, a partir de então, tornou-se rotineira nos processos de reconhe- 
cimento e demarcação de terras indígenas. Uma vez que às comunidades indígenas não se aplica o conceito de posse civil, foi preciso fazer uso de uma perícia antropológica para identificar a ocupação imemorial de território pelos índios. Foi com base nela que se pôde reconhecer a área do Parque do Xingu como terra da União, identificada sob a figura jurídica da Terra de Ocupação Tradicional Indígena, definida na tradição jurídica brasileira a partir da Constituição de 1934, e, nesse caso, caracterizada sob o título de um Parque Nacional. Com isso, o curso das ações foi revertido e o assalto aos cofres públicos evitado.

Se a lógica que ordena o princípio indigenista da proteção supõe uma relação, no fim das contas conformada como aliança implícita, entre o Estado Nacional e os seus "protegidos", os povos indígenas, contra os interesses locais da exploração econômica irracional e do usufruto, é bastante evidente também que, apesar dessa generalidade formal, os contextos e contingências políticas variaram consideravelmente, produzindo até mesmo o que poderíamos chamar de "proteção ambígua" (por assim reservar-nos o direito ao eufemismo), operada, não obstante, a partir dos termos e princípio da lógica da proteção, e fazendo uso dos mecanismos institucionais criados sob seu abrigo. A década de 70 do século XX, já sob o contexto de referências territoriais do que chamamos de "modelo amazônico", representa provavelmente a culminação dessas "ambiguidades". Ela se deu exatamente por ocasião da maior intensificação, promovida pelo Estado Nacional e no contexto de um regime político autoritário, da expansão da fronteira agrícola e da exploração econômica, sob a forma do extrativismo empresarial ilimitado (e, por consequência, social e ambientalmente descontrolado) da Amazônia. Na medida em que uma específica conformação política de controle do Estado dava mãos livres à predação promovida pelos novos agentes colonizadores (e considerava isso proveitoso e virtuoso), o pacto implícito da proteção via-se consideravelmente esvaziado.

A imagem da "nacionalidade" herdada por alguns setores militares que se caracterizam como os remanescentes da "linha dura" é tributária dessa racionalidade da predação, para a qual aquilo que possa ser o seu inverso, como a "preservação das culturas indígenas", não poderia ser outra coisa (segundo o imperativo excludente da sua lógica maniqueísta) senão uma ameaça alienígena à "segurança nacional", como bem expressou o general Cláudio Barbosa de Figueiredo. Ou seja, apesar de pretender tomar emprestado para si, de forma postiça, o legado rondoniano, não é, em absoluto, o princípio da sua lógica que generais como esse pretendem honrar, mas tão apenas, isso sim, o legado autoritário. Tal legado não expressa necessariamente uma postura nacionalista (como consistentemente o demonstra o sentido global do modelo econômico da dependência, alentado pelos governos militares), mas antes a pretensão de fazê-lo, a partir de uma específica concepção da nacionalidade, em favor da qual trabalham também (ou conspiram) alguns oportunos fantasmas.

Essa mais recente "tradição militar" vem se manifestando, esporádica mas 
persistentemente, desde o chamado "retorno do país à normalidade democrática". Curiosamente, nessa fase, a Amazônia foi alçada à condição de seu reduto simbólico. Pode-se até mesmo considerar que a constituição desse reduto (reitere-se: antes de mais nada, simbólico) operou-se na mesma medida em que, num outro espaço simbólico e institucional, o do país urbano, "complexo", "moderno", consagrouse discursivamente o repúdio da sociedade civil a essa tradição militar autoritária. Outra forma de dizê-lo, ainda que com todos os riscos das categorizações simplificadoras, é sugerir que: onde mais os espaços institucionais foram "preenchidos" pela sociedade, menos restou para compor a engenharia totalizante do Estado suposta pela geopolítica. A Amazônia e a presunção do seu vazio a conquistar (Lima, 1990) consumariam, nesse caso, o quadro inverso, ou seja, o espaço simbólico onde o significado da soberania nacional suporia um certo "preenchimento" ideal pelo Estado, cuja ação encarnaria os "interesses nacionais permanentes" (conforme o jargão conceitual dos manuais da doutrina da Segurança Nacional). A isso não é preciso mais que acrescentar que o caráter (ou o "conteúdo") dessa ocupação estatal é - como observamos, e muito distintamente da perspectiva rondoniana - a ocupação econômica predatória. Em suma, com essa economia simbólica do Estado, o que falta ao pensamento militar tributário da tradição autoritária é, tão simplesmente, a possibilidade de compreender a sociedade.

No fim das contas, a "preocupação amazônica" induzida pela (ou no corpo da) tradição militar autoritária é tanto subsidiada por elementos factuais relativos às novas fronteiras de um patrimônio (considerado estritamente, nesse caso, como riqueza material) do país quanto pela sobrevivência de elementos discursivos de uma lógica da tutela política, qual seja, a da recusa implícita da diversidade de pensamento, que nesse caso inclui também, sintomaticamente, as culturas indígenas, com a consequente negação peremptória de que essa desafiante alteridade possa porventura ser "preservada". O renovado refrão "a Amazônia é nossa", insinuado por alguns ideólogos militares, desvela, assim, a sua ambígua significação objetiva: "nossa" no sentido de que ela atenda ao projeto (ou à pretensão) de ser açambarcada como propriedade simbólica de uma tradição autoritária, diante da qual todo o resto precisa ser necessariamente estrangeiro, alienígena. Ao orientar-se pelo primado da exclusão, e não pela inclusão potencial da alteridade, torna-se uma obviedade meramente redundante constatar que essa tradição não se filia, de modo algum, ao legado rondoniano.

O caso de Roraima e da Terra Indígena Raposa/Serra do Sol, nesse sentido contextual mais próximo, não é nem isolado, nem aleatório. Seus nexos simbólicos devem ser buscados na confrontação com o caso da Terra Indígena Yanomami ante o projeto Calha Norte, já no começo do novo período democrático. Também ali, os militares consideravam aquela Terra Indígena um empecilho à "segurança nacional". Também ali uma similar conjunção de interesses defendia a sua demarcação em "ilhas". E também ali, em 1991, o antropólogo Bruce Albert (1991, p.53) notava que 
$39 \%$ dos territórios indígenas da faixa de fronteira norte-amazônica estão [estavam] com o seu subsolo loteado e bloqueado por títulos minerários, constituindo-se numa considerável reserva de mercado de empresas de mineração, em particular, de empresas privadas nacionais.

Se os índios, sobretudo as novas comunidades contatadas, sobreviveram (não sem um custo considerável) às ameaças da "proteção ambígua” e aos imperativos do discurso da Segurança Nacional da tradição militar autoritária foi porque novos (e até mesmo decisivos) componentes entraram na equação política da proteção, fazendo uso, igualmente, da sua lógica básica. Se a mobilização de uma parcela da sociedade civil, na década de 1970, constituída por antropólogos, jornalistas, religiosos e sertanistas, entre outros, começou a constituir as bases de uma rede social de apoio à “causa indígena”, logo seria necessário expandir esse arco de alianças para o campo internacional. Ele funcionou não apenas por dentro dos mecanismos institucionais do indigenismo de Estado, como também fez uso da pressão de instituições internacionais e, finalmente, conformou a rede institucional de um "indigenismo alternativo" cuja função, diante dos mecanismos regulatórios formais, ainda é fundamentalmente complementar e, com bastante segurança, não tem outra forma de ser (ao menos enquanto a questão indígena for uma questão pública).

Ou seja, tais alianças pró-indígenas pressupõem o Estado, pois têm como fundamento o exercício de pressão sobre os seus poderes para demandar a sua intervenção "civilizadora" (contra a intrusão desregulada e os lobbies da predação), ao mesmo tempo que a legitimam como prerrogativa desse Estado, o único que pode respaldar a efetividade dos direitos indígenas. Os termos da proteção podem ter ganhado novas mediações e uma nova complexidade, mas suas relações lógicas fundamentais permanecem. Seria, assim, anacrônico presumir que a ação de um indigenismo assistencial possa representar uma ameaça ao Estado ou à soberania, a não ser que se presuma como ideal para o Estado retirar-se da regulação de direitos coletivos, retirando, ao mesmo tempo, tal regulação do espaço público e tornando-a, por fim e em todos os termos, insubsistente.

$\mathrm{Na}$ verdade, para além da mera especulação, das miragens e dos fantasmas, só o que resta como base objetiva, para que, a partir dela, os recentes ideólogos militares possam vislumbrar uma "ameaça” à soberania nacional, é o reconhecimento de uma coletividade amparada legalmente como tal, como se toda e qualquer nacionalidade não pudesse abrigar mais que a indivíduos. $\mathrm{O}$ espantalho dos direitos coletivos é provavelmente muito próximo ao fantasma do comunismo. Compreende-se que para alguns militares isso pareça ideologicamente ameaçador. Daí que constitua uma ameaça à soberania nacional, não deixa de ser uma enorme miopia política, tão característica, aliás, da tradição militar autoritária. Compreende-se assim a preocupação expressa pelo general Luiz Gonzaga Schroeder Lessa em uma de suas notas para o website do Clube Militar, ao horrorizar-se: 


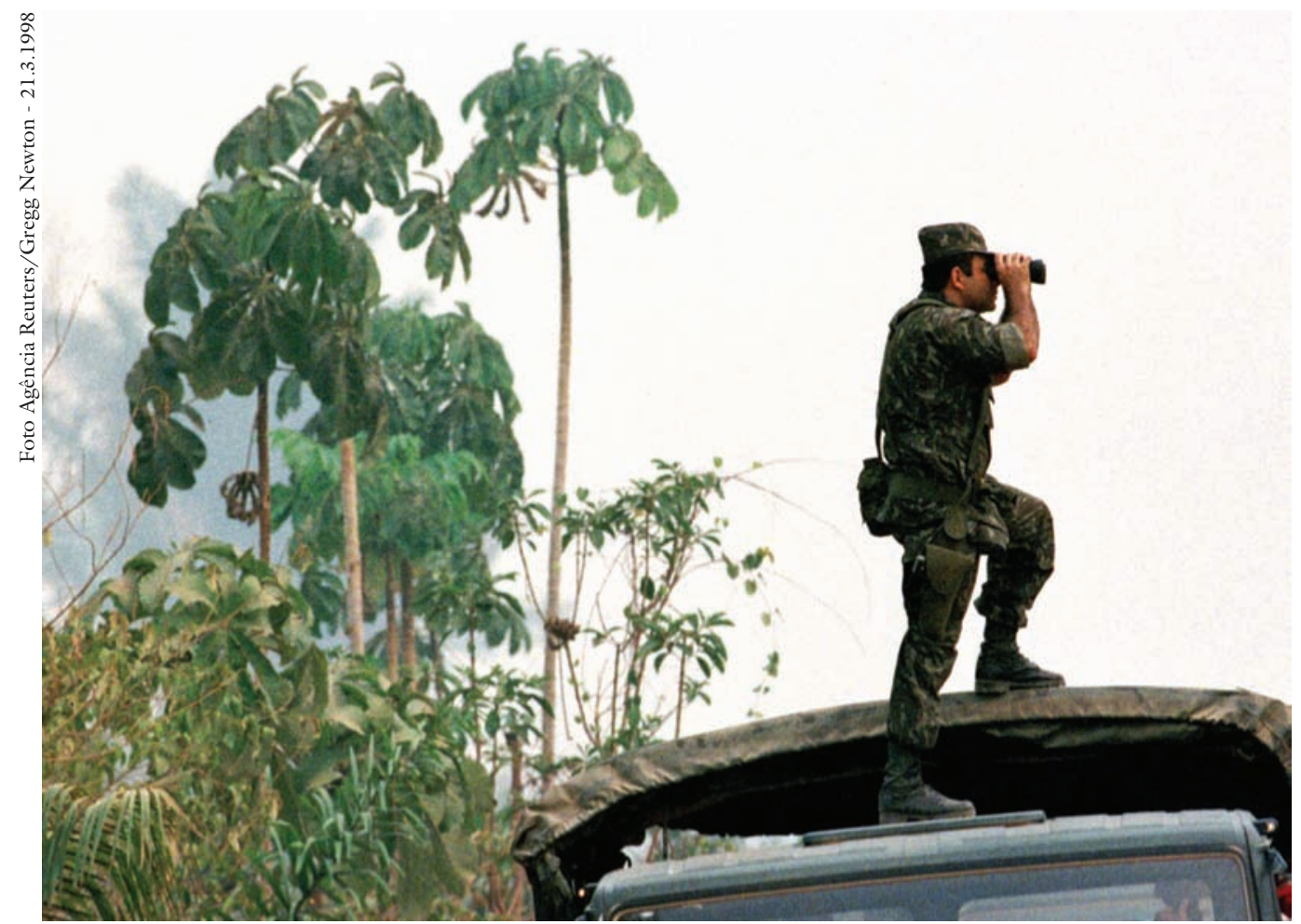

Tenenete do Exército utiliza binóculo para identificar foco de incêndio em Roraima (RR).

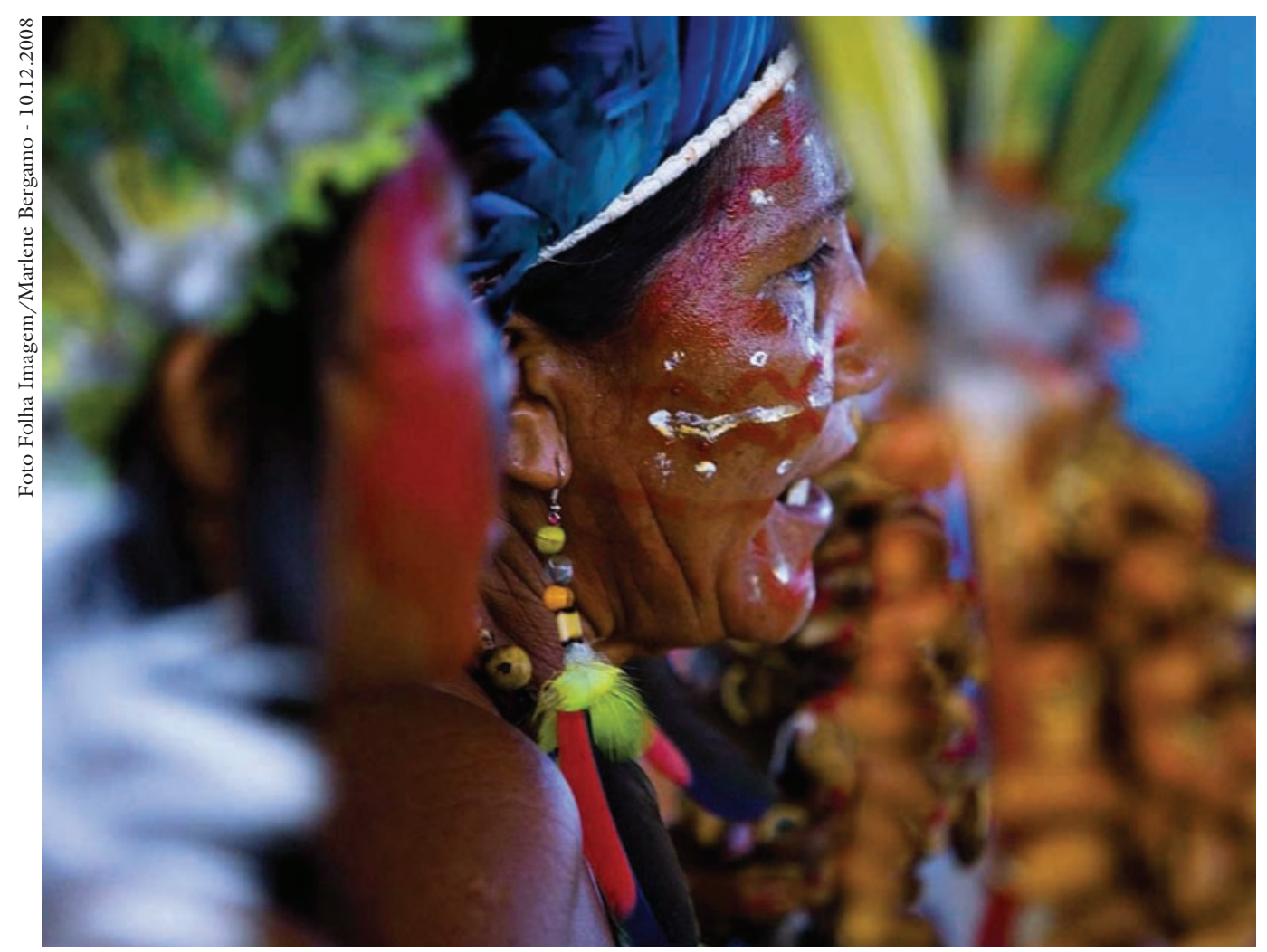

A pajé Mariana Tobias na Terra Raposa/Serra do Sol, na Vila Sumuru, em Roraima. 
A longa e polêmica Declaração [Universal dos Povos Indígenas, aprovada pela ONU] é um instrumento internacional que modifica a ênfase nos direitos individuais e, pela primeira vez, valoriza os "direitos humanos coletivos" e atribui às comunidades indígenas a posse do território onde vivem e dos seus recursos naturais, bem como o direito coletivo à autonomia. ${ }^{10}$

Como já se demonstrou historicamente, o que mais uma vez se reitera aqui é que a ideologia da Segurança Nacional, patrocinada pela tradição militar autoritária, ainda que com novas ênfases, não tem necessariamente como preocupação central a soberania, mas apenas uma específica forma de regulação social, que se pretende universal e impositiva. A retórica da soberania e a construção de fantasmas ameaçadores foram e continuam sendo apenas o seu pretexto. Nesse sentido, o fantasma da "balcanização" não significa outra coisa que a expressão da aversão à diversidade; uma diversidade que, uma vez expressa sob o amparo de direitos coletivos, não tem como ser resolvida politicamente, nos termos dessa lógica, senão como ameaça.

As insistentes defesas públicas que, após o caso do general Heleno, alguns militares fizeram do velho assimilacionismo, pretendendo reduzir a ele o significado do legado rondoniano e sugerindo-o como único sentido possível para uma política indigenista que não seja nem "caótica”, nem "ameaçadora”, seguramente representam, por si sós, uma forma de totalitarismo étnico. Mas o espírito autoritário - ou, no melhor dos casos, simplesmente etnocêntrico - que o alenta não será de todo apreendido se não se reconhece, como também próprio dele, a pretensão de exclusividade de um certo tipo de regulação social, na qual a única base possível de direitos é o indivíduo.

Considerações como essas evidentemente incidem sobre um debate contemporâneo que se desdobra sob a égide conceitual da diferença no espaço social. O que elas nos sugerem também é que não se trata de fazer simplesmente um elogio genérico à diferença e a uma diversidade retórica, mas de se ponderar sobre o estatuto dessa diferença, ou seja, sobre o que ela incide, a partir de quais critérios e segundo qual regime. Se a diferença cultural e a especificidade de uma memória social - que subsidiam, em último termo, o reconhecimento da existência dos povos indígenas - se fundamentam sobre a partilha coletiva de um sentido de mundo, só há razão, portanto, para falar de coisa como "direitos étnicos" precisamente se são assumidos como direitos coletivos, irredutíveis ao mero usufruto individualista (como, do contrário, uma nova conformação da tradição liberal se esforça por consagrar, ao patrocinar coisas como políticas de $\left.\operatorname{cotas}^{11}\right)$.

Reiteramos: a maior ameaça que no fim das contas ronda a cabeça de certos ideólogos militares é a "ameaça” dessa diversidade de sentidos de mundo e sua legitimidade; exatamente o que o pensamento autoritário (militar ou não) não admite, apesar de sua eventual tintura de boas intenções, pincelada sobre uma retórica de defesa da soberania. 
1 Apesar de, uma semana antes, o general Heleno ter qualificado publicamente a demarcação em território contínuo da Terra Indígena Raposa/Serra do Sol, em Roraima, como um "risco à soberania nacional", nesse momento ele não se referiu diretamente ao caso, preferindo condenar a política indigenista brasileira como um todo, qualificando-a de "lamentável e caótica" e "que não deu certo", a partir de um critério de julgamento tão impressionista quanto imponderável: "é só ir lá para ver". Na mesma ocasião, o chefe do Estado Maior do Comando Militar do Leste e ex-comandante da 1 a Brigada de Infantaria de Selva, em Roraima, general Mário Matheus de Paula Madureira, foi mais específico sobre as terras indígenas: "O risco da soberania é com áreas que podem ser separadas do território brasileiro. ONGs internacionais e grupos indígenas podem solicitar essa divisão política. Pode ser a mesma situação que ocorreu no Kosovo" (cf. reprodução da matéria jornalística de $O$ Globo, disponível em: <http:// www2.senado.gov.br/bdsf/item/id/94257>. Acesso em: 12.5.2008).

2 Consultem-se, por exemplo, os sites: <http://www.brasilsoberano.com.br>; <http:// alertatotal.blogspot.com>; <http://www.alerta.inf.br e http://www.msia.org.br>.

3 Noticiou o jornalista Roldão Arruda, em O Estado de S. Paulo, em 6.4.2008: "Em entrevista ao Estado, o general da reserva Durval de Andrade Nery, da direção do Centro Brasileiro de Estudos Estratégicos (Cebres), que congrega no Rio os Clubes Naval, Militar e da Aeronáutica, disse enfaticamente que o Exército não participa [das operações de desintrusão em Raposa/Serra do Sol] porque não concorda com a retirada dos 'brasileiros não-indígenas' da reserva. Apesar de convidados, os militares não participaram das reuniões de preparativos da operação. Mas sabiam que seria iniciada no dia 28. E por isso o Cebres realizou, na sede do Clube da Aeronáutica, nos dias 26, 27 e 28, o seminário Amazônia, Cobiçada e Ameaçada - com um time de palestrantes contrários à demarcação. 'Fizemos isso exatamente para mostrar que o Exército não apóia essa operação', assegurou Néry" (Disponível em: <http://www.estadao.com.br/estadaodehoje/20080406/not_impl52040,0.php>. Acesso em: 10.5.2008). Entre os palestrantes do seminário mencionado antes estiveram o ministro da Defesa, Nelson Jobim, o ministro da Agricultura, Pecuária e Abastecimento, Reinhold Stephanes, o senador Mozarildo Cavalcanti (PTB-RR), a senadora Kátia Regina de Abreu (DEM-TO), o exchefe do escritório da Agência Brasileira de Inteligência (Abin) em Roraima, diretores da Confederação Nacional da Agricultura e cinco oficiais-generais das três forças. Sobre a ação do Cebres em torno do caso Raposa/Serra do Sol, consultem-se ainda as matérias: "Roraima, arroz e banho de sangue" (disponível em: <http://jbonline.terra.com. br/editorias/pais/papel/2008/04/06/pais20080406003.html>); "Exército se opõe a ação em Roraima" (disponível em: <http://www.estadao.com.br/estadaodehoje/20080406/not_impl52040,0.php>); "Militares rejeitam a ONU em demarcação na Amazônia" (disponível em: <http://www.agenciaamazonia.com.br/index.php?Ite $\mathrm{mid}=259 \& \mathrm{kid}=2484$ \&option $=$ com_content\&task=view $>$ ).

4 Disponível em: <http://www.clubemilitar.com.br/site/pres/balcanizar.htm>. Acesso em: 5.5.2008.

5 Cf. Folha de S.Paulo, São Paulo, 24.4.2008. Link para assinantes: <http://wwwl.folha.uol.com.br/fsp/brasil/fc2404200812.htm>. Acesso em: 5.5.2008.

6 Ainda que o DEM (Democratas) tenha emitido uma nota pública de apoio aos pronunciamentos do general Heleno, a insinuação da sua convocação para manifestar-se no Congresso não foi consumada. 
7 Esse dado foi levantado por um rondoniano convicto, Darcy Ribeiro (1970, p.250), e publicado num livro dedicado à memória do marechal.

8 Não confundir com o então presidente do Clube Militar, general Gilberto Barbosa de Figueiredo.

9 Cf. <http://portal.rpc.com.br/gazetadopovo/opiniao/conteudo.phtml?tl=1 \&id=76 3210\&tit=Reflexoes-sobre-a-questao-indigena $>$. Acesso em: 12.5.2008.

10 Cf. <http://www.clubemilitar.com.br/site/pres/soberania.htm>. Acesso em: 5.5. 2008.

11 Reportamo-nos, sobretudo, ao projeto de "cotas raciais" que, baseado na premissa da "distribuição desigual de desigualdades", se apresenta como a mais atualizada fórmula liberal de justiça (cf. Raws, 1971). Argumentado sob um pretexto no mínimo duvidoso de pertencimento "étnico-racial” de indivíduos avulsos, tal projeto opera, na verdade, sobre aquilo que em outro lugar chamamos de "uma fé fundamentalista na diferença naturalizada” (Cavalcanti-Schiel, 2007, p.269).

\section{Referências bibliográficas}

ALBERT, B. Terras indígenas, política ambiental e geopolítica militar no desenvolvimento da Amazônia: a propósito do caso yanomami. In: LÉNA, P.; OLIVEIRA, A. E. de. Amazônia: A fronteira agrícola 20 anos depois. Belém: Museu Paraense Emílio Goeldi, 1991. p.37-58. (Col. "Eduardo Galvão").

CARNEIRO DA CUNHA, M. Legislação indigenista no século XIX. In: CARNEIRO DA CUNHA, M. (org.). História dos índios no Brasil. São Paulo: Cia. das Letras; Fapesp; Secretaria Municipal de Cultura, 1992. p.133-54.

CAVALCANTI-SCHIEL, R. Quando nem todos os cidadãos são pardos. In: FRY, P. et al. Divisões perigosas. Políticas raciais no Brasil contemporâneo. Rio de Janeiro: Civilização Brasileira, 2007. p.263-70.

LEIRNER, P. de C. O Exército e a questão amazônica. Estudos Históricos, Rio de Janeiro, n.15, p.119-32, 1995.

LIMA, A. C. de S. Indigenismo e geopolítica: projetos militares para os índios no Brasil. In: OLIVERIA, J. P. de. Projeto Calha Norte. Militares, índios e fronteiras. Rio de Janeiro: Editora da UFRJ, 1990. p.60-86. (Série “Antropologia e Indigenismo", n.1).

MINISTÉRIO DA SAÚDE. Fundação Nacional de Saúde (Funasa). Anexo. Relação da população indígena cadastrada no Siasi/Funasa e proposta de distribuição dos valores referentes ao IAB-PI, por município - 2007. In:__. Atenção básica e especializada aos povos indigenas. Brasília: Fundação Nacional de Saúde, 2007. p.23-40.

MONTEIRO, J. M. Tupis, tapuias e a história de São Paulo. Revisitando a velha questão guaianá. Novos Estudos Cebrap, São Paulo, n. 34, 1992, p.125-35

PINTO, L. F. Três reflexões sobre segurança nacional na Amazônia. Estudos Avançados, São Paulo, v.16, n.46, p.131-40, 2002.

RAWLS, J. A theory of justice. Harvard: Harvard University Press, 1971.

RIBEIRO, D. Os índios e a civilização: a integração das populações indígenas no Brasil moderno. Rio de Janeiro: Civilização Brasileira, 1970. 
RESUMO - Recentemente, vozes do meio castrense brasileiro voltaram a insistir que as terras indígenas na Amazônia representam uma ameaça à soberania nacional. Nesse tipo de manifestação, que é em realidade um ataque retórico aos direitos indígenas estabelecidos sob o lastro de uma longa tradição indigenista, as críticas militares pretenderam, em nome da "segurança nacional", desqualificar a totalidade dessa política de Estado. Este artigo observa não apenas o anacronismo de tais críticas ante a tradição indigenista brasileira e sua filiação a uma tradição autoritária mais recente, mas também como os elementos discursivos desta última confrontam-se agora com novos debates sobre a regulação social, ante a noção de diferença e significado que, com relação a ela, podem ser postulados os direitos coletivos.

PALAVRAS-CHAVE: Indigenismo, Militares, Amazônia, Segurança Nacional.

ABSTRACT - Some Brazilian military voices have recently turned to condemn indigenous lands in Amazonia as a threat to national sovereignty. Under this manifestation (actually, a rhetorical attack to indigenous rights established by a large indigenist tradition), military criticism try to discredit the State indigenist politics as a whole. This article appreciates both the anachronism of these critics regarding the large Brazilian indigenist legal tradition and their affiliation with a more recent authoritarian tradition; but it also observes how discursive elements of this last one (the authoritarian tradition) face the new debate about social regulation, regarding the notion of difference and the meaning of collective rights concerned to it.

KErWORDS: Indigenism, Military, Amazonia, National Security.

Ricardo Cavalcanti-Schiel é antropólogo, mestre e doutor pelo Museu Nacional (UFRJ). Está atualmente vinculado ao Laboratoire d'Anthropologie Sociale do Collège de France/École des Hautes Études en Sciences Sociales

@ - riccaval@bol.com.br

Recebido em 31.6.2008 e aceito em 5.8.2008. 